\title{
Filicide-suicide or a suicide pact? A case report from Sri Lanka with implications for child protection
}

\author{
M Hewagama, S G H Abeypitiya, V Dharmawardene
}

\section{Abstract}

Parents almost always are protective of their offspring. However, rarely they could be deadly towards children, specially when psychologically disturbed or disordered. In this brief report we discuss an incident of filicide-suicide that rocked Southern Sri Lanka a few years ago. In this incident, a father and three of his four children were found dead by hanging, due to an apparent suicide pact. There were warning signs and concerns raised prior to the incident which did not receive notable assertive action from authorities, as their concerns were limited to sexual abuse, which was found to be negative. This report explores possible motives of the father, as well as lessons for personnel from mental health services, child protection and police for when confronted with children who are in the custody of parents who could pose threat to their life. This case also highlights the need for comprehensive risk assessment and not merely the risk of sexual abuse.

SL J Psychiatry 2021; 12(2): 31-35

\section{Introduction}

The natural instinct in most parents is to protect their offspring. Parental behavior has evolved over millions of years to enhance chances of projecting one's own genes to the future, via offspring. Filicide - the act of parents killing one's own child or children - goes against this evolutionary principal (1). The global rate of filicide is unknown and many perpetrators of filicide, especially of young children, are reported to successfully conceal their crime (2). There are a number of differences between men and women who kill their children (3). Fillicidal fathers are known to have criminal records, kill older children and to be psychotic less often than fillicidal mothers (3).

Most reputed schemes of classification of filicide highlight the motivational or impulse related factors behind the act, where the perpetrator's original aggression is seen as displaced from partner/wife, sibling or parent towards a more vulnerable target; the child (4). Most men who commit filicide have been raised in environments characterized by violence, abuse, have experienced separation from or of parents, and many have had severe behavioral problems and psychiatric treatment, beginning in their childhood (5).

A suicide pact is the mutual arrangement between two or more people who resolve to carry out an act to die at the same time, nearly always in the same place, and these pacts may occur due to non-ideological reasons, usually among family members, mostly spouses, or among friends
(6). When a pact involves a parent and a child or children, it is almost always the parent who instigates the pact and on many occasions the parent is mentally unwell (7). In a case where chidlren are involved, it is often difficult to establish how competent they were, especially as a child is vulnerable to persuasion and often lacks the power to resist a parental order to obey, irrespctive of competency. In addition, even though children are able to understand the act of suicide, they lack the adult competency to understand the consequences (7).

Here we report a case of death of a 41-year-old father and his three teenage children, in a possible filicidesuicide event, or in what appeared to be a suicide pact apparently instigated by the father, who killed himself after the children ended their lives. We also attempt to reconstruct the circumstances and the mental state of the father at the time that led to this filicide-suicide or suicide pact, in order to understand the nature of the incident, while highlighting the warning signs that could alert clinicins and other agencies in preventing similar incidents in the future.

\section{Case Report}

The bodies of 41-year-old Mr P and three of his four children aged 10, 14, 16 years were found hanging from a bamboo pole strung across two trees in front of the family home in Kamburupitiya, in the Matara District, Sri Lanka. The house had apparently been set on fire by $\mathrm{Mr}$ $\mathrm{P}$ on the day of the incident (Figure 1). The youngest 
and oldest deceased children were girls. The 14-year old boy was a novice monk who resided in a nearby temple, who had been fetched home by $\mathrm{P}$ a few days before the incident.

The bodies of the three children were found with their hands tied with minimal abrasions or wounds (Figure 2). A bag was found hung on the end of a pole on the clothesline in the garden, containing several hand-written notes including two suicide notes (Figure 3). One suicide note was from $\mathrm{P}$ and the other was purportedly a joint suicide letter signed by the three children in the handwriting of the oldest of the three (identified by the police) (Figure4). In the letter the children had written that they did not want to live any longer without their mother (P's wife) as they could not perform the household work and due to the distress caused to them by rumors circulating in the village alleging incest in their family.

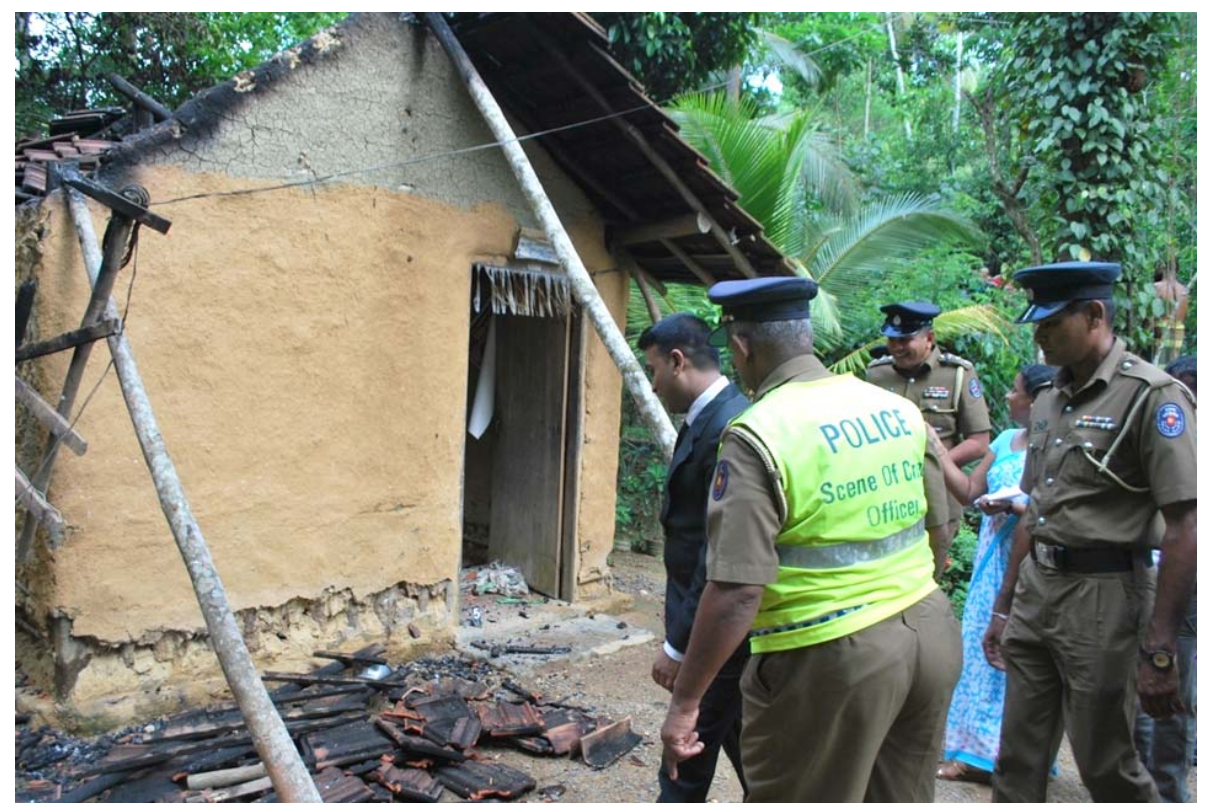

Figure 1.

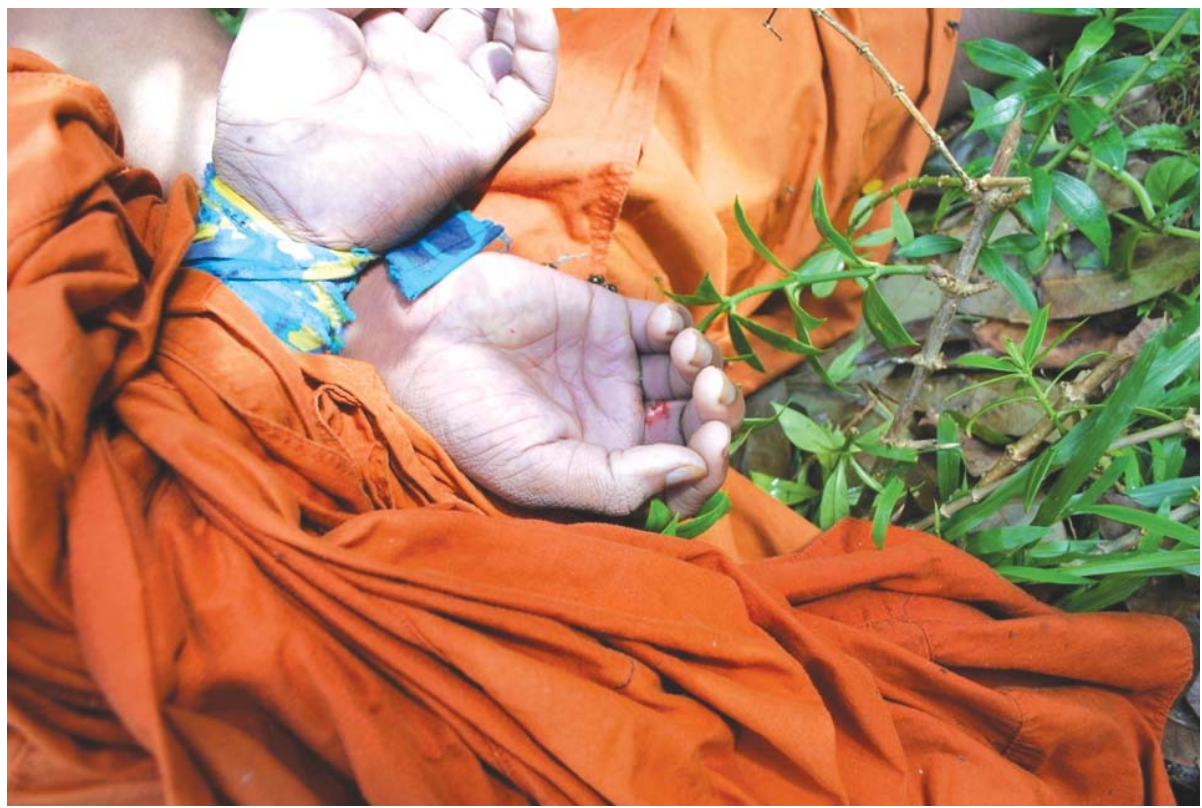

Figure 2. 


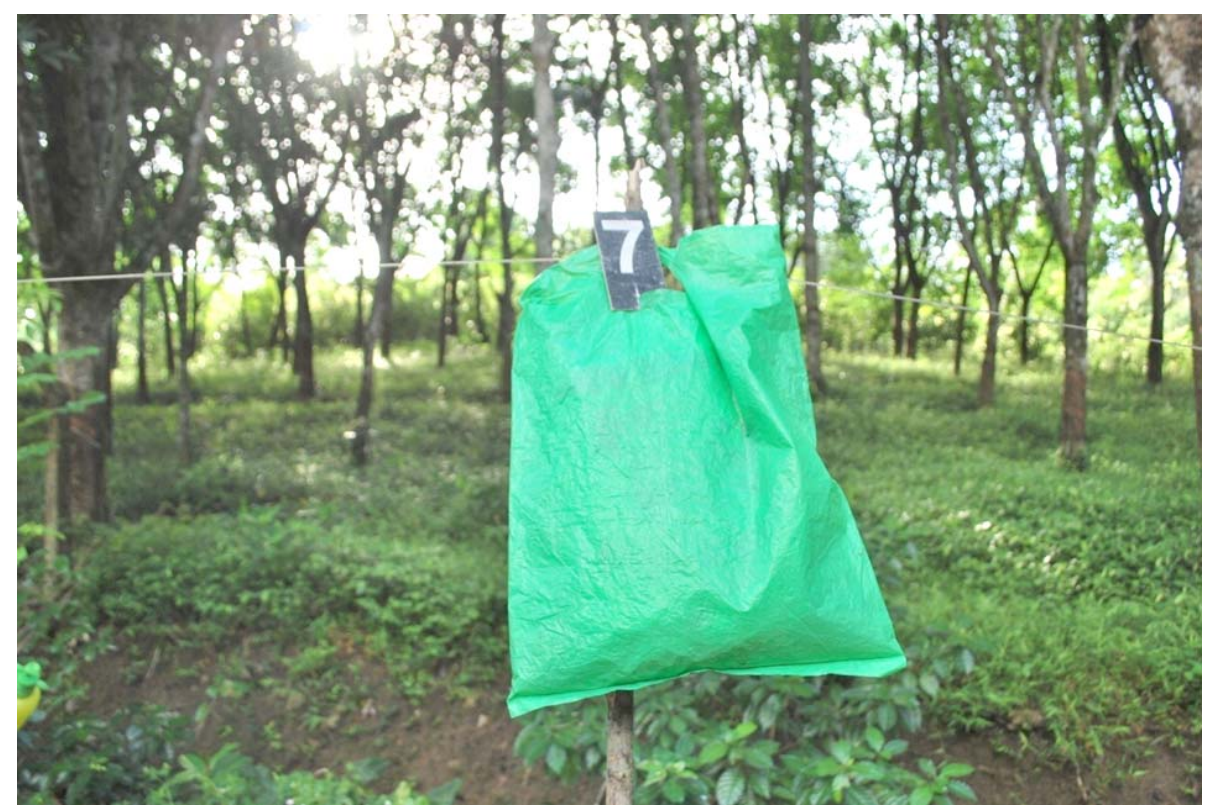

Figure 3.

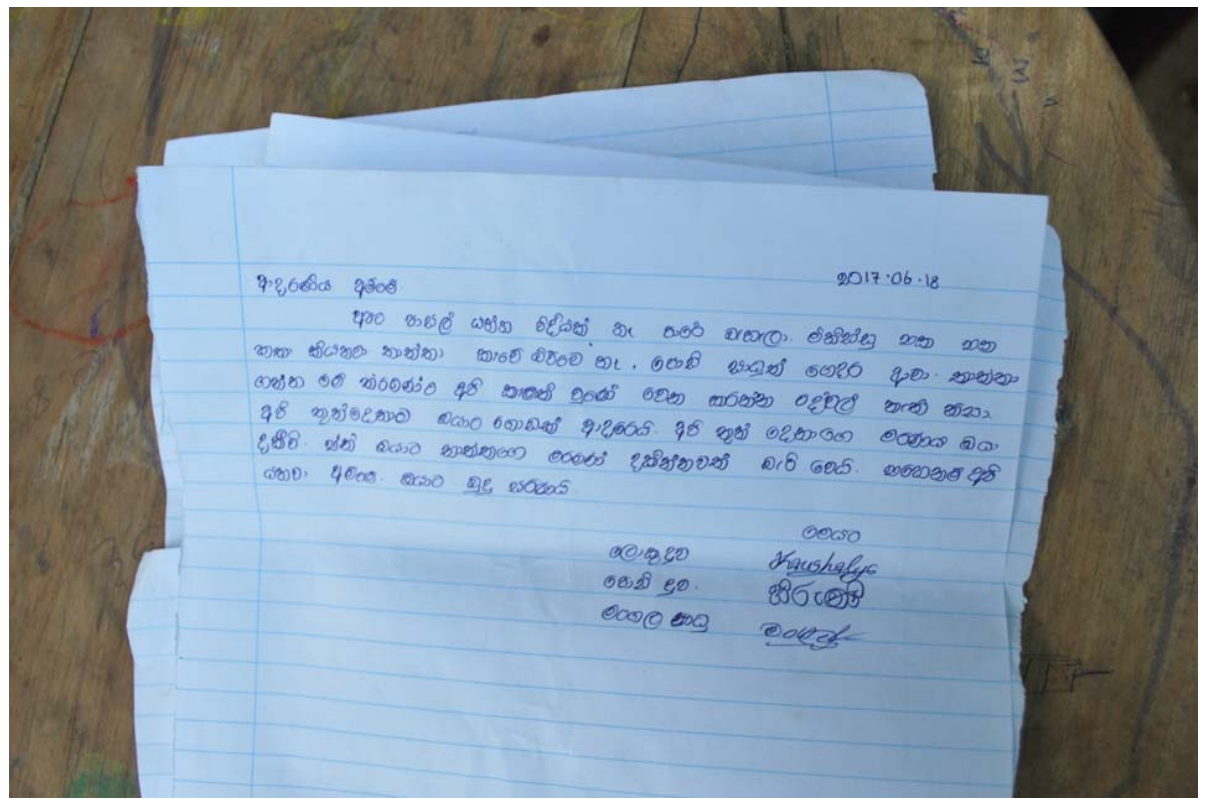

Figure 4.

The authors carried out face to face and telephone interviews with Mrs S (wife of P), P's father, brother, and sister-in-law, the Grama Niladari of the village, the child welfare officer (CWO) of the area, officer in charge of the Kamburupitiya police station and the principal of the school which the two girls attended.

P appeared to have had a very difficult childhood, where he was physically abused by his father and also probably witnessed regular acts of domestic violence and possible incestual acts by his father towards his sister. P had been expelled from school in Grade 10 for his aggressive and disruptive behavior and since then had worked as an unskilled labourer.
$\mathrm{P}$ had married $\mathrm{S}$ after a romantic relationship, and in addition to the three children who died in the above incident, they also have another son (17 years old) who is a monk, living in a distant temple. According to $\mathrm{S}, \mathrm{P}$ had displayed regular, pathological patterns of behaviour characterized by threats and acts of violence, deliberate self-harm, destroying property including setting his house on fire, killing and maiming animals and repeated physical assaults of his two sons for trivial reasons, throughout their marriage.

He appeared to have suspected his wife of infidelity for a considerable time, however it is unclear whether this was delusional in nature. He had also repeatedly accused 
his father and brother of wanting to steal his property, leading him to be estranged from them over a number of years. There had also been periods of excessive alcohol use, but this had substantially reduced towards the last two years of his life.

S reported that during the last two years she had concerns regarding $\mathrm{P}$ abusing their older daughter sexually, which had led her to leave him and live separately with the children for a short time. However, she said she had been forced to return with the children due to P's unending cajoling, threats and her poor financial status.

She reported that she made several complaints of domestic violence to the police, but according to her none of these were ever documented or investigated. She said she did not inform the authorities of her suspicions about the daughter being sexually abused, as she wanted to avoid the social stigma of such a disclosure. S finally left P in May 2017 but she reported that her two daughters refused to leave with her, despite her reasoning with them. It appeared that $\mathrm{S}$ viewed this as a betrayal of her by the daughters.

According to the other informants, a number of government officials, such as the police and CWOs had been alerted regarding the children's living situation at this time, by various sources, including anonymous calls alleging that $\mathrm{P}$ was sexually abusing his children. We were informed that even though an investigation had been initiated, it had not been pursued lengthily due to insufficient information. The school authorities whom we interviewed had not observed any emotional distress in the two girls after their mother left the family home in 2017. However, P's relatives had noticed that he had become socially withdrawn during this time and that his alcohol use had reduced as mentioned above.

\section{Discussion}

$P$ fits the profile of a "typical filicidal father" in the literature (5). The threats of self-harm, domestic violence and setting fire to his house prior to 2017, indicate his probable poor impulse control and a possibility of a major mental illness, such as depression and or delusional disorder. Alcohol may have played a role, but it is not clear whether $\mathrm{P}$ was under the influence of alcohol at the time of the incident. Previous studies indicate that most parents responsible for filicide either have a history of psychiatric contact and/or ongoing symptoms of a mood or thought disorder, at the time of the act (9).

The incident we describe appears to be well planned, with several letters written and visible attempts having been made to blame the wife and absolve $P$ if responsibility for the act. It is arguably an example of filicide motivated by the desire for "spousal revenge" (5). We also hypothesize that, even if this was a true suicide pact, it (as written in the letter by the children which stated "we agree to father's plan as there are no other options") may have been instigated by a father, who was most probably was mentally ill, and the participants were three dependent and vulnerable children.

In our opinion, there had been many warning signs that could have alerted the authorities about the dangers posed to the children. It could be argued that errors in judgement may have led to underestimation of the risk posed to the children, preventing the child protection staff from acting assertively. We were informed that at one point the authorities contemplated placing the children in a home of a teacher of the school, in the context of claims of sexual abuse. However, this had not been carried out, as the investigation conducted at the time did not find any evidence to support these claims. It is also noteworthy that the autopsy findings failed to find any evidence of penetrative sex involving the two girls. It should be highlighted that the overemphasis given to child sexual abuse can derail the agencies from looking into other risks posed to the children (10).

It is not clear whether a valid, overall approach was taken by different staff who assessed the risk. Recording of statements without a formulation based on consideration of the overall multiple risk factors in this situation, appears to be a deficit in the child protection procedures which unfortunately has become evident only after the tragedy. We also hypothesize that the fact P was known to the police, CWOs and other authorities, may have precluded them from obtaining a compulsory mental health evaluation of him, which may have changed the course of events for this family.

This case indicates the complex nature and the multifaceted formulation needed to assess risks towards children from their legal guardians who may cause them harm, and that when such cases are investigated it is important to consider the multiple dimensions of risk towards children, and not merely the risk of child sexual abuse.

\section{Author contributions}

$\mathrm{MH}$ and VD conducted the interviews and wrote the manuscript. VD did the literature search. SGHA did the forensic examination. All authors have seen and approved the final draft.

\section{Conflicts of interest}

None declared 
M Hewagama, S G H Abeypitiya, District General Hospital, Matara, Sri Lanka

V Dharmawardene, Teaching Hospital, Ratnapura, and Faculty of Medicine, University of Sabaragamuwa, Sri Lanka

Corresponding author: V Dharmawardene

Email: vajiradharmawardene@yahoo.com

D http://orcid.org/0000-0003-4794-4749

\section{References}

1. Gross MR. The evolution of parental care. Q. Rev. Biol. 2005; 80: 37-45.

2. Koenen MA, Thompson JW, Jr Filicide. Historical review and prevention of child death by parent. Infant Mental Health Journal 2008; 29(1): 61-75.

3. Marks MN, Kumar R. Infanticide in England and Wales, 1982-1988. Medicine, Science, and the Law, 1993. 33: 329-39.
4. Scott PD. Parents who kill their children. Medicine, Science and the Law $1973 ; 13: 120-6$.

5. Debowska A, Boduszek D, Dhingra K. "Aggression and Violent Behavior Victim, perpetrator, and offense characteristics in filicide and filicide - suicide", Aggress. Violent Behav. 2015; 21: 113-24.

6. Cohen J. A study of suicide pacts. Medico-legal Journal 1961; 29: 144-51.

7. Sarkar S, Srinivas B, Grover S. Quadruple pact suicide attempt involving a man and three adolescents. Indian $\mathrm{J}$ Psychol Med. 2014; 36(4): 422-24. doi:10.4103/0253-7176.140736

8. Friedman S, Hrouda D, Holden C, et al: Filicide-suicide: common factors in parents who kill their children and themselves. Am Acad Psychiatry Law 2005; 33: 496-504.

9. Latha KS. Suicide pact survivors: some observations. Med Sci Law. 1996; 36(4): 295-8. doi:10.1177/002580249603600404

10. Dharmawardene V. Interventions for sexually abused children - a mismatch between evidence and practice is harmful to children. Journal of the Ruhunu Clinical Society, 2016; 21(1): 2-4. DOI: http://doi.org/10.4038/jrcs.v21i1.13 